\title{
Towards streaming as a dominant mode of media use?
}

\author{
A user typology approach to music \\ and television streaming
}

\author{
Marika Lüders, ${ }^{\text {I }}$ Vilde Schanke Sundet, ${ }^{I} \&$ Terje Colbjørnsen ${ }^{\mathrm{II}}$ \\ IDepartment of Media and Communication, University of Oslo, Norway \\ ${ }^{\mathrm{II}}$ Department of Archivistics, Library and Information Science, OsloMet, Norway
}

\begin{abstract}
Music and television streaming services present users with abundant catalogues of content available on demand. We investigate whether users respond by narrowing or widening the diversity of content they consume. Further, we examine how the different logics characterising music and television streaming are mirrored in the number of streaming services people use. To do so, we compare non-, sporadic, regular, and frequent users of television and music streaming services. Findings from a cross-sectional survey in Norway show that frequent streamers consume a wider variety of genres and rely on more services. Our results also indicate that streaming has gone from a first-mover activity to a standard consumer mode. This study indicates that we can expect continued growth in television streamers, whereas the music streaming industry seems more consolidated.
\end{abstract}

Keywords: media industries, music, streaming, television, users

\section{Introduction}

Hipsters may love LPs, but streaming has, by and large, replaced old forms of purchasing and listening to music. Thus far, television streaming has not supplanted linear ways of watching, but the transformative dimensions of Internet-distributed television have implications for programming, production, circulation, and consumption of content (Johnson, 2019; Lotz, 2017, 2018; Turner, 2019). For users, music and television streaming represent a mode of accessing content with some shared characteristics: abundant catalogues of content are made available on demand. This combination of abundance and agency (where both components can be questioned) brings us to the core question of this article: Do users respond by narrowing or widening the diversity of content they consume? That is, do they primarily choose to follow their favourite

Lüders, M., Sundet, V. S., \& Colbjørnsen, T. (2021). Towards streaming as a dominant mode of media use? A user typology approach to music and television streaming. Nordicom Review, 42(1), 35-57. https://doi.org/10.2478/nor-2021-0011 
preferences, or do they take advantage of the variety of content available? Moreover, since music streaming services offer overlapping libraries of music, relying on one service provider likely suffices even for listeners with diverse preferences. Television streaming services, by contrast, compete on differentiated content (Johnson, 2019). In this article, we argue that a granular distinction beyond users and non-users is required in order to examine how streaming affects content consumption and how users adapt to the different configurations of providers characterising the music and television streaming market.

Media and communication researchers tend to pay less attention to these issues, and instead address questions of practices and sense-making. Studies of music streamers have contributed knowledge on how people make sense of social features (Hagen \& Lüders, 2017), playlisting practices (Hagen, 2015; Sinclair \& Tinson, 2017), and the role of algorithms and discovery (Kjus, 2016; Lüders, 2019, 2020; Nowak, 2016). Research on the use of television streaming services has examined how people watch multiple episodes in succession - that is, "binge-watching" or "marathon viewing" (Merikivi et al., 2018; Pittman \& Sheehan, 2015; Steiner \& Xu, 2018; Sung et al., 2018). Others study adoption and use of new formats for watching television (Leung \& Chen, 2017; Oyedele \& Simpson, 2018; Tefertiller, 2018) or find that users of music and television streaming services tend to be younger and male (Gerpott \& Meinert, 2019; Leung \& Chen, 2017; $\mathrm{Li}, 2020)$. Similar patterns are found in statistics on use of online distributed music and television in Norway (Schiro, 2020).

Streaming hence opens numerous avenues for research, but few compare music and television streaming, or examine associations between use of streaming services and content consumption. Such enquiries should take into account how people differ in the extent to which they use streaming services. Using data from a representative survey conducted in Norway in 2018, we therefore categorise users as frequent, regular, sporadic, and non- users. We first analyse how these types of users differ regarding the number of television genres watched and music genres listened to. Research indicates that algorithmic recommendations help people discover and expand their taste in music (Lüders, 2019; Nowak, 2016). However, we do not know whether such experiences apply to television streamers, or even to music streamers beyond the avid music listeners typically enrolled as study subjects. We next examine whether there are differences between the number of services used by different types of streamers before investigating their demographic composition. Throughout the article, we pay particular attention to frequent users, since those who use streaming services most extensively likely portray patterns of use most markedly informed by the logics of streaming services.

The Norwegian market is small but technologically mature, and it has served as a strategic test market for streaming services. Spotify launched in Norway in 2008, and Netflix entered in 2012 - using the Norwegian market as an international testing ground for its "all-at-once-watching model" (Sundet, 2016). In both industries, incumbent national players have created their own services. These include Wimp for music (later re-branded and sold internationally as Tidal), and services for audiovisual content from public service broadcasters NRK (NRK player) and TV 2 (TV 2 Sumo), commercial broadcasters TVNorge (Dplay) and TV3 (Viaplay), and the leading tabloid news provider VG (VGTV). The mixed structure hosting both national and international streaming services has created an advanced streaming market. Consequently, our study encapsulates 
a historically significant time when markets and user habits are changing; however, not necessarily at the same pace within music and television.

We proceed by first turning to the logics of music and television streaming as a step towards understanding why and how we expect these to partly inform user practices. We then present our hypotheses, method, and analytical approach. The analysis shows that frequent streamers consume a wider variety of genres and that streaming has become common across sociodemographic variables. We conclude by discussing the implications of our study.

\section{The logics of streaming}

Since music and television industries have different logics (Herbert et al., 2019; Hesmondhalgh, 2019), the impact of streaming may also differ. Such differences partly account for why comparative cross-industry approaches are needed; we cannot infer insights from one domain to another. On the other hand, music and television represent comparable sectors regarding a shift towards streaming. All types of streaming services arguably offer "temporary and contingent on-demand access to vast content databases for a fixed fee paid on a regular basis, or for exposure to advertising, and through an internet-connected device" (Colbjørnsen, 2020: 5). Additionally, public broadcasters have streaming services. While technological infrastructures and business models vary, the user experience is similar by offering choice and convenience for users (Spilker $\&$ Colbjørnsen, 2020). Unlike more industry-specific approaches, our broad conceptualisation of streaming hence includes subscription-based services like Spotify and Netflix, public service streaming such as NRK TV, and ad-funded streaming such as YouTube.

We continue by attending to the extent to which the logics of television and music streaming differ. Our focus is on aspects that might help us discern how streaming encourages certain user practices. We do not propose that media users succumb to these logics, but emphasise the importance of delineating the interrelations of technology, formats and actors as a step to investigate use of streaming services. Furthermore, we build our argument on the basis that industry logics are influenced by "streaming lore" (Burroughs, 2019), that is, the conventional knowledge among industry insiders on how streaming affects both media culture and audience behaviour in a time of change (see also Havens \& Lotz, 2012).

First, streaming services amplify contemporary high-choice media environments, situating media users in a position where they are free to follow their own content preferences (Prior, 2005). A concern for research has been how abundance and choice affect people's media consumption, including to what extent diversity in available content is reflected in exposure diversity (Moe et al., 2020; Prior, 2005; Sjøvaag, 2016). Yet, the idea that users are free to follow their content preferences needs to be critically considered, and increased user agency is a contested notion in critical research examining the structuring forces of streaming services. Television and music streaming services structure how users meet content with interfaces, menus, and algorithms, and service providers hence retain significant control with what content users are guided towards (Johnson, 2019; Morris \& Powers, 2015). A key question is consequently whether this control is applied to encourage users to expand or narrow their content repertoires. For services that rely on tracking user data to tailor content to what algorithmically catego- 
rised users will like (Beer, 2019; Burroughs, 2019; Lobato, 2019; Lotz, 2017; Smith \& Telang, 2016), it remains uncertain whether personalisation contributes to diversify consumption. It should also be noted that whereas Netflix relies on behavioural data for personalising content (Burroughs, 2019, Lobato, 2019), national television providers such as NRK and TV2 are still in the process of optimising personalisation (Hjertaas, 2019). In comparison, the most widely used music streaming services in Norway all offer personalised playlists based or partly based on machine learning algorithms (e.g., Spotify's “Daily Mix”, Apple Music's “For You”, and Tidal's “My Mix”).

Second, streaming services for music and television are structured differently regarding content and variety of service providers. Music streaming services have largely overlapping libraries of music (Morris \& Powers, 2015). Streaming services for television are different, with content libraries representing crucial assets in the competition for viewers (Johnsen, 2019). Because content libraries differ across providers, audiences may need to rely on several providers to match their preferences (Herbert et al., 2019). Television streaming also encompasses a wider variety of service providers. A few music streaming providers have dominant market positions, though which providers dominate varies between countries (Wikström, 2013). The situation for television streaming is different. Global and national vertical television conglomerates offering streaming as part of their service ecosystem co-exist with global subscription-based services (Johnsen, 2019; Lotz, 2017). Domestic broadcasters have also launched streaming-video players to retain market shares. Such strategic actions are essential because global providers tailor their services and content to local markets (Lobato, 2019).

Third, both domains are characterised by a variety of business models (Spilker \& Colbjørnsen, 2020; Herbert et al., 2019; Lotz, 2017; Sinnreich, 2016). For television, the subscriber-funded model contrasts with the legacy model of gathering mass audiences for the advertisement market (Lotz, 2017). For music, streaming marks a departure from the transaction-based economy associated with the sale of LPs, CDs, and downloadable files. Ad-supported services and public service providers further complicate the picture, bypassing the subscription model by taking advantage of other revenue sources. In Scandinavian countries, the public service model has stayed comparatively stable (Bruun, 2020). This co-existence of various models further motivates our broad conceptualisation of streaming. While substantially different, they all provide users with on-demand access to abundant catalogues of content.

\section{Hypotheses}

Our first hypothesis concerns the number of genres consumed, and based on the literature, we expect diverging patterns between television and music streaming services. High-choice audiovisual media environments are not necessarily mirrored in people consuming a variety of content, but on the contrary, may increase the impact of content preferences (Prior, 2005). Our study, however, is not well suited to investigate exposure diversity, a field of research largely focused on the consequences of increased user choice for news consumption (Moe et al., 2020; Prior, 2005; Sjøvaag, 2016). Such enquiries require rigorous examinations of the same genres across media (Schrøder, 2015). What our data enable us to examine is a cruder form of exposure diversity in the sense of genres consumed through streaming services characterised by abundant content 
libraries, on-demand access, and (various levels of) personalisation and algorithmic recommendations. While subscription-based streaming could be expected to encourage users to maximise "bang for the buck", such associations do not necessarily play out as a variety of genres consumed. Instead, since viewers are freed from the flow schedules of broadcasters, they may be incentivised to follow their content preferences rather than watching "what's on". Additionally, if binge-viewing is a prominent practice (Merikivi et al., 2018; Pittman \& Sheehan, 2015; Steiner \& Xu, 2018; Sung et al., 2018), such viewing patterns might narrow the variety of genres watched. For music, however, research points to how avid listeners use recommendations to widen their taste in music (Lüders, 2019; Nowak, 2016), and we hence expect frequent use of streaming services to be associated with listening to a larger volume of genres. We therefore hypothesise the following:

H1a. Frequent users of television streaming services watch fewer genres compared with those who do not use streaming services extensively.

H1b. Frequent users of music streaming services listen to more genres compared with those who do not use streaming services extensively.

Our second hypothesis concerns the number of streaming services used. We expect those who use streaming services extensively to rely on more services. Aligned with our broad definition of streaming, services here denote a wide variety of providers (subscriptionbased, ad-funded, and publicly funded). Since television streaming services compete on offering different content libraries (Herbert et al., 2019; Johnson, 2019), we also expect frequent television streamers to use more services compared with frequent music streamers. Our second hypothesis is therefore:

H2. Frequent streamers are more likely to use more services. These associations will be more prominent for television streaming services compared with music streaming services.

With our third hypothesis, we examine how categories of users differ demographically. Younger males are more likely to be early adopters of streaming services (Leung \& Chen, 2017; Li, 2020). Our study does not, however, investigate early adopters, but rather a later phase, if applying Rogers's (2003) diffusion of innovations perspective. Music and television streaming services are no longer novelties, and our interest is in typologising users beyond a crude measure of users versus non-users. This approach implies understanding how different segments differ in their use of streaming services instead of understanding who starts using these services first. While frequent users have not necessarily been early adopters, we expect age and gender to remain differentiators of frequent streamers. Our third hypothesis is therefore:

H3. Frequent users of television and music streaming services are more likely to be younger (H3a) and male (H3b), but do not differ regarding education (H3c) or income (H3d) compared with those who do not use streaming services extensively.

Finally, to what extent do users belong to the same category of streamers across industries? Are frequent television streamers also frequent music streamers? There is little prior evidence to build on regarding potential overlaps in user types. We therefore ask the following research question: 
RQ. Do users belong to the same category of streamers across industries?

\section{Method}

This study is based on data from a survey, with a representative sample of the Norwegian population, conducted in October 2018 by the research agency Kantar TNS. A stratified probability sample of 1,511 respondents was recruited from Kantar's web panel of 46,000 participants. Post-stratification weights $($ minimum $=.415$; maximum $=2.536$ ) allow the sample to match the composition of the Norwegian population on age, sex, and education.

\section{Measures}

The demographic variables included gender, age, level of education, and level of income (reduced to three levels for the analysis; see Table 1).

To measure use of streaming services, respondents were asked to report approximately how many minutes they had streamed television, watched linear television, and streamed music the day before answering the survey. Respondents were also asked which of nine listed television streaming services (Amazon Prime, Dplay, HBO Nordic, Netflix, TV2 Sumo, NRK player, VG TV, Viaplay, and YouTube) they had ever used, with a follow-up question of how long it had been since they last used those services (yesterday, 2-7 days, 8-30 days, 1-12 months, or longer). Respondents were likewise asked which of seven listed music streaming services (Apple Music, Amazon Music, Google Play Music, Soundcloud, Spotify, Tidal, and YouTube) they had ever used, with a follow-up question of how long it had been since they last used those services (using the same scale as for television). Respondents reported which of nine listed television genres they had streamed and watched on linear television during the last seven days. ${ }^{1}$ Likewise, respondents reported which of 23 listed music genres they had listened to during the last seven days. ${ }^{2}$

A new variable for types of television-streaming users was computed based on time since last using at least one television streaming service and time spent streaming the previous day. ${ }^{3}$ Non-users did not use any television streaming services during the last 30 days $(N=245)$. Sporadic users did not stream television the day before answering the survey but had used at least one television streaming service 8-30 days prior $(N=$ 86). In order to typologise the remaining respondents, we also considered how much time they had spent streaming television the previous day. A frequency analysis showed that the top 20 per cent of all respondents had streamed television for 120 minutes or more, and we used this as a first step to identify frequent streamers. Regular users had streamed television the previous day, but for less than 120 minutes $(N=376)$, or they had not streamed television the day before, but they had used at least one television service during the last seven days $(N=231)$. Frequent users had streamed television for more than 120 minutes the previous day and had consequently also used at least one television streaming service during the last seven days $(N=311)$. This variable excludes 262 respondents from further analysis. These were respondents who replied in inconsistent ways, for example, reporting to have streamed television the day before, but without having used any television streaming services. 
A new variable for types of music-streaming users was computed following the same procedure as for types of television streamers. The initial frequency analysis showed that the top 20 per cent had streamed music for 60 minutes or more the day before answering the survey, and this was hence used as the initial cut-off for identifying frequent streamers. The new variable for types of music-streaming users - also considering whether respondents reported having used any streaming services during the last 8-30 days (sporadic) or the previous seven days (regular) - includes 402 non-users, 129 sporadic users, 455 regular users, and 354 frequent users. This variable excludes 171 respondents from further analysis for the same reasons as for types of television-streaming users. Figure 1 depicts the percentage shares for types of television and music streamers. Almost three-quarters of respondents are regular and frequent users of television-streaming services. The corresponding share of regular and frequent users of music-streaming services is 60 per cent.

\section{Figure 1 Types of streamers (per cent)}

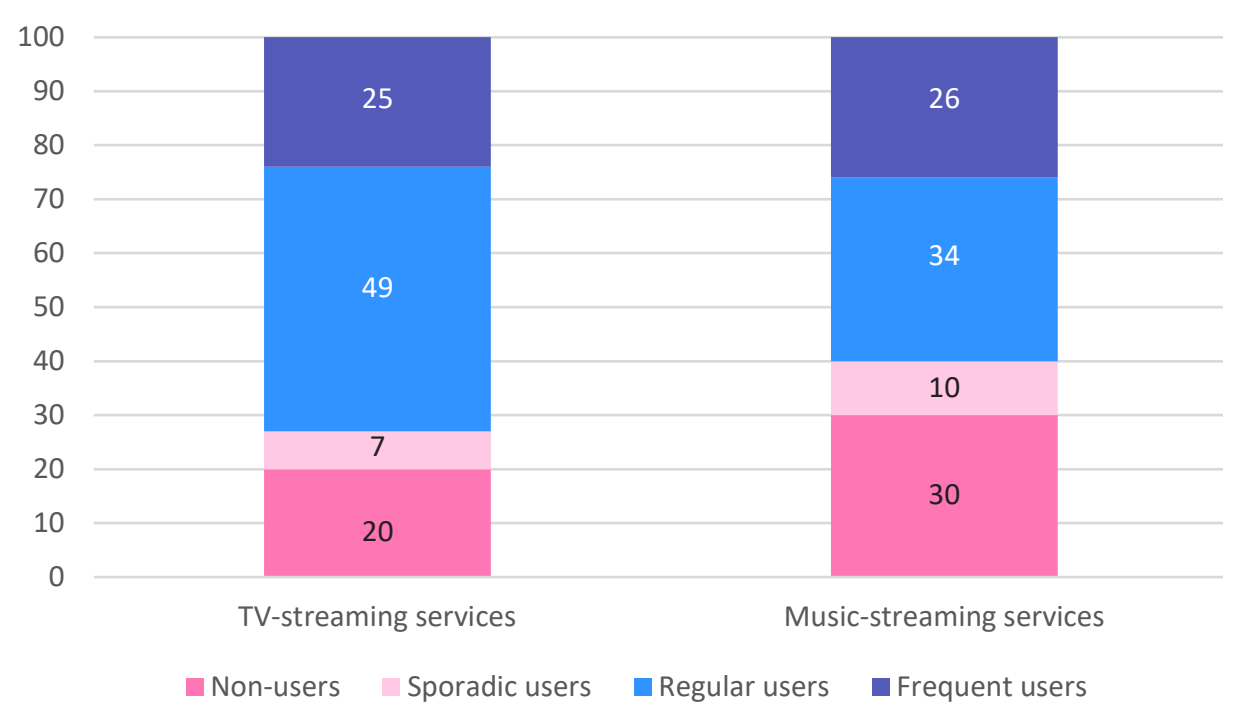

Comments: $N=1,249$ for TV-streaming services; $N=1,340$ for music-streaming services. Non-users used no streaming services during the last 30 days. Sporadic users did not stream the day before answering the survey, but used at least one streaming service 8-30 days prior. Regular users streamed the day before but for less than 2 hours for TV or less than 60 minutes for music, or they used at least one streaming service during the last 7 days. Frequent users streamed TV for more than 120 minutes or music for more than 60 minutes and also used at least one streaming service during the last 7 days.

Table 1 provides descriptive statistics for demographic variables and variables for use of streaming services and shows that the samples for types of television streamers and music streamers remain similar to the demographics of the full sample. 
Table 1 Descriptive statistics (weighted)

\begin{tabular}{|c|c|c|c|}
\hline & $\begin{array}{c}\text { Full sample } \\
(N=1,511)\end{array}$ & $\begin{array}{l}\text { TV-streamers sample } \\
\qquad(N=1,249)\end{array}$ & $\begin{array}{l}\text { Music-streamers } \\
\text { sample }(N=1,340)\end{array}$ \\
\hline Female (\%) & 49.5 & 50 & 49.5 \\
\hline $\mathrm{Age}^{\star}$ & $47.3(17.6)$ & $47.2(17.7)$ & $47.3(17.7)$ \\
\hline \multicolumn{4}{|l|}{ Education (\%) } \\
\hline primary education & 9 & 9 & 9 \\
\hline upper secondary school & 58 & 56 & 58 \\
\hline higher education $<4$ years & 19 & 20 & 20 \\
\hline higher education 4 years + & 14 & 15 & 14 \\
\hline \multicolumn{4}{|l|}{ Income (\%) } \\
\hline$<$ NOK 300,000 & 23 & 24 & 24 \\
\hline NOK 300,000-599,999 & 49 & 48 & 47 \\
\hline NOK 600,000 + & 16 & 16 & 17 \\
\hline don't want to answer & 12 & 12 & 12 \\
\hline \multicolumn{4}{|l|}{ Television* } \\
\hline $\begin{array}{l}\text { minutes of streaming TV day } \\
\text { before survey }\end{array}$ & $54.1(82.6)$ & $59.3(86.4)$ & $52.9(80.6)$ \\
\hline $\begin{array}{l}\text { minutes watching linear TV day } \\
\text { before survey }\end{array}$ & $66.8(89)$ & $63.9(87.6)$ & $68.3(91.3)$ \\
\hline $\begin{array}{l}\text { number of streaming services } \\
\text { used last } 30 \text { days }\end{array}$ & $2.5(2.0)$ & $2.5(2.0)$ & $2.5(2.0)$ \\
\hline $\begin{array}{l}\text { number of genres streamed last } \\
7 \text { days }\end{array}$ & $2.1(2.0)$ & $2.1(2.1)$ & $2.0(2.0)$ \\
\hline $\begin{array}{l}\text { number of genres watched on } \\
\text { linear TV last } 7 \text { days }\end{array}$ & $2.9(2.2)$ & $2.8(2.3)$ & $2.9(2.3)$ \\
\hline \multicolumn{4}{|l|}{ Music* } \\
\hline $\begin{array}{l}\text { minutes streaming music day } \\
\text { before survey }\end{array}$ & $45.4(71.4)$ & $46(73.1)$ & $48.7(73.5)$ \\
\hline $\begin{array}{l}\text { number of streaming services } \\
\text { used last } 30 \text { days }\end{array}$ & $1.2(.94)$ & $1.2(.96)$ & $1.1(.96)$ \\
\hline $\begin{array}{l}\text { number of genres listened to last } \\
7 \text { days }\end{array}$ & $3.4(3.2)$ & $3.4(3.2)$ & $3.4(3.2)$ \\
\hline
\end{tabular}

Comments: TV-streamers sample and music-streamers sample include respondents categorised as non-users.

*Mean values with standard deviations in parentheses.

\section{Analytic approach}

For $\mathrm{H} 1$ and $\mathrm{H} 2$, types of television and music streamers serve as predictor variables, with number of genres watched and listened to during the previous seven days, and number of services used during the last 30 days as outcome variables. Both outcome variables are continuous. Therefore, separate one-way between-groups analyses of variance were conducted to examine the impact of types of users.

For H3, demographic variables serve as predictor variables, with types of streamers as outcome variables. Types of streamers (from non-user to frequent user) is an ordinallevel variable, and we considered using ordinal logistic regression. However, our models did not meet the parallel lines assumption. Multinomial logistic regression can also be 
used for ordinal outcome variables and does not assume parallel lines (Denham, 2010). We first conducted cross tabulations for each demographic variable and types of streaming users to determine which variables to include in the multinomial logistics regression analysis. Predictor variables can be categorical and continuous. In our models, we have one continuous predictor (age), and three categorical predictors: gender, education (dichotomised), and income (dichotomised).

\section{Results}

\section{How do types of users differ concerning genres consumed and services used?}

In addressing our first and second hypothesis, we first examine differences between types of television streamers regarding the number of genres watched and the number of services used. We then continue with the same set of tests for differences between types of music streamers.

To determine user-patterns between types of television streamers, respondents were asked to report what television genres they had watched during the last seven days. We computed a new variable for each television genre, counting a genre being watched if the respondent had either streamed the genre or watched it on linear television. ${ }^{4}$ Figure 2 indicates that the total number of genres are quite similar across types, but with regular and frequent streamers being more diverse in the content they watch. Figure 4 shows that non-users and sporadic users watch more genres on linear television compared with regular and frequent users. Combined, Figures 3 and 4 indicate that frequent users stream more genres than they watch on linear television.

Figure 2 Number of television genres watched the last seven days (mean)

$$
6
$$

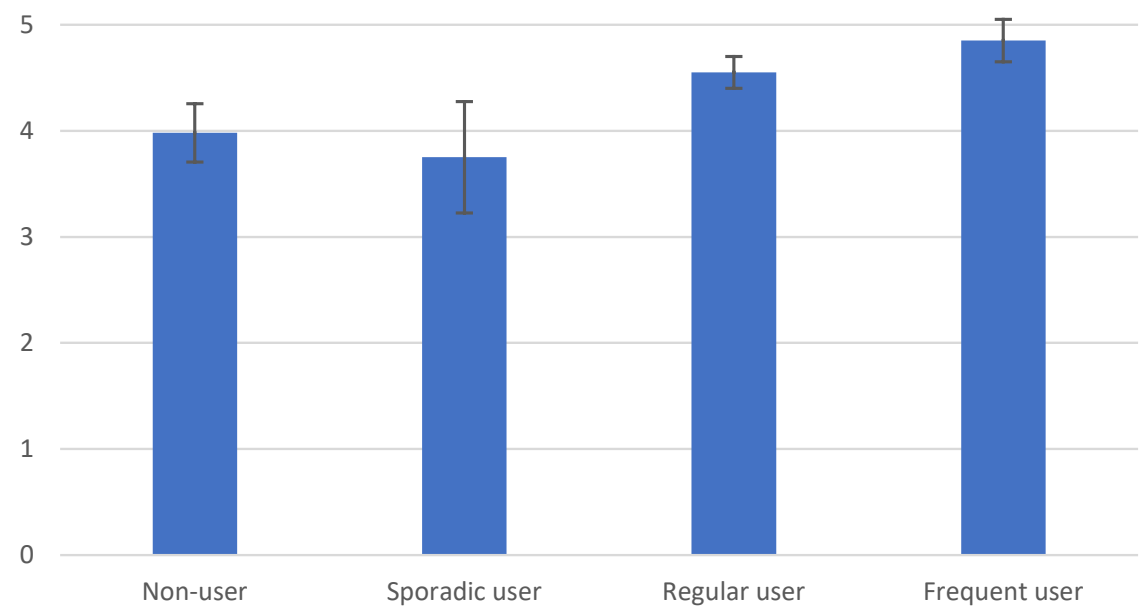

Comments: Error bars: $95 \% \mathrm{Cl}$. Non-users used no TV-streaming services during the last 30 days. Sporadic users did not stream the day before answering the survey, but used at least one streaming service 8-30 days prior. Regular users streamed TV the day before, but for less than 120 minutes, or they used at least one streaming service during the last 7 days. Frequent users streamed TV more than 60 minutes and also used at least one streaming service during the last 7 days. 
Figure 3 Number of television genres streamed last seven days (mean)

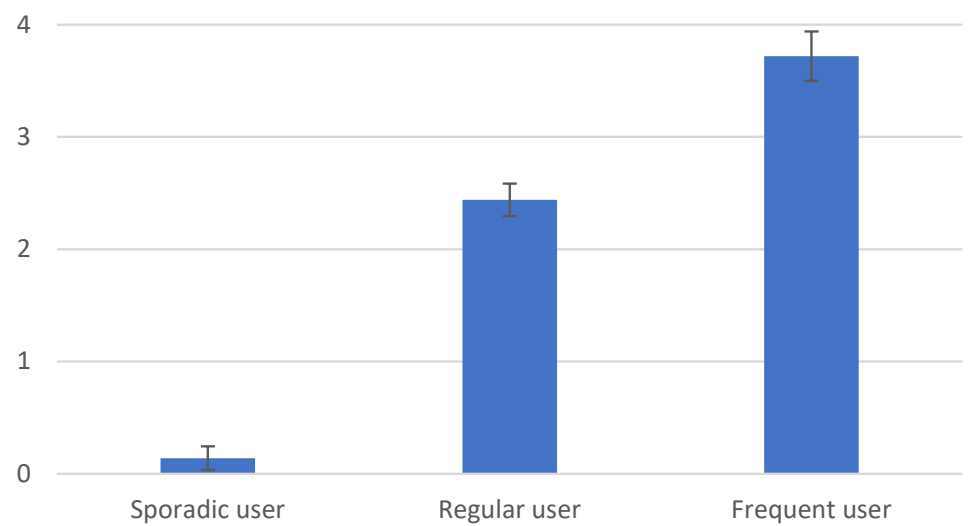

Comments: Errorbars: $95 \% \mathrm{Cl}$. Non-users used no TV-streaming services during the last 30 days. Sporadic users did not stream the day before answering the survey, butused atleastonestreamingservice8-30days prior. RegularusersstreamedTVthedaybeforebutforlessthan 120 minutes, ortheyusedatleastone streamingserviceduringthelast7days. FrequentusersstreamedTVformorethan 120 minutesandalsousedatleastonestreamingserviceduringthelast 7 days.

Figure 4 Number of genres watched on linear television last seven days (mean)

5

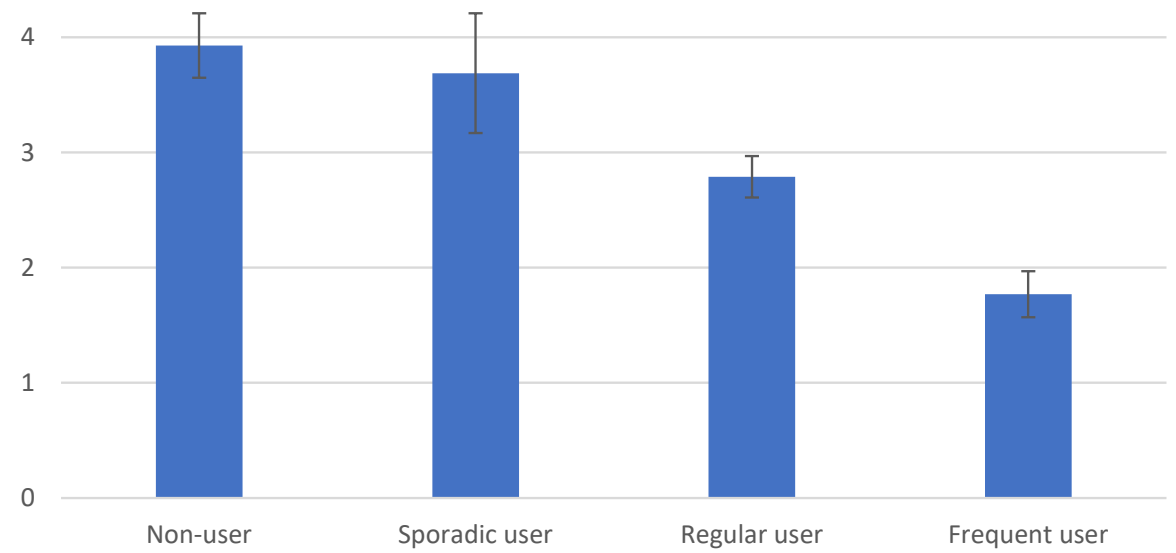

Comments: Error bars: $95 \% \mathrm{Cl}$. Non-users used no TV-streaming services during the last 30 days. Sporadic users did not stream the day before answering the survey, but used at least one streaming service 8-30 days prior. Regular users streamed TV the day before but for less than 120 minutes, or they used at least one streaming service during the last 7 days. Frequent users streamed TV for more than 120 minutes and also used at least one streaming service during the last 7 days.

A one-way between-groups analysis of variance was conducted to examine differences between total number of genres watched (linear and streamed). The differences between groups are statistically significant, $F(3,495.96)=10.21, p<.001$ (Welch's $F$ ). The effect size, calculated using omega squared $\left(\omega^{2}\right)$, is small $\left(\omega^{2}=.02\right)$. Post-hoc comparisons using the Tukey HSD test indicate that the mean scores for non-users $(\mathrm{M}=3.99, \mathrm{SD}=$ $2.1)$ is statistically different from regular users $(\mathrm{M}=4.63, \mathrm{SD}=1.8)$ and frequent users $(\mathrm{M}=4.7, \mathrm{SD}=1.95)$, but not from sporadic users $(\mathrm{M}=4.25, \mathrm{SD}=1.92)$. 
A one-way between-groups analysis of variance suggests that frequent streamers use significantly more services during a 30-day period compared with other groups, $F(2$, $327.67)=185.54, p<.001$ (Welch's $F$ ). The effect size is large $\left(\omega^{2}=.12\right)$. Post-hoc comparisons indicate that the means scores for sporadic users $(\mathrm{M}=1.47, \mathrm{SD}=.78)$, regular users $(\mathrm{M}=3.1, \mathrm{SD}=1.67)$, and frequent users $(\mathrm{M}=3.75, \mathrm{SD}=1.71)$ are significantly different between all groups.

To determine user-patterns between types of music streamers, respondents were asked what genres they had listened to during the last seven days, without specifying whether music was streamed or whether they listened to music using CDs, vinyl, or purchased digital files (but excluding radio and similar). Figure 5 indicates a clear association between types of users and the number of genres listened to, with number of genres increasing correspondingly with type of streamer. The differences between the groups are statistically significant, $F(2,521.56)=135.61, p<.001$ (Welch's $F$ ). The effect size is large $\left(\omega^{2}=.22\right)$. Post-hoc comparisons indicate that the mean scores for non-users $(\mathrm{M}=1.51, \mathrm{SD}=2.06)$, sporadic users $(M=2.03, S D=1.95)$, regular users $(M=3.97, S D=2.93)$, and frequent users $(\mathrm{M}=5.25, \mathrm{SD}=3.65)$ are significantly different between all groups, except for a non-significant difference between non-users and sporadic users.

Figure 5 Number of genres listened to last seven days (mean)

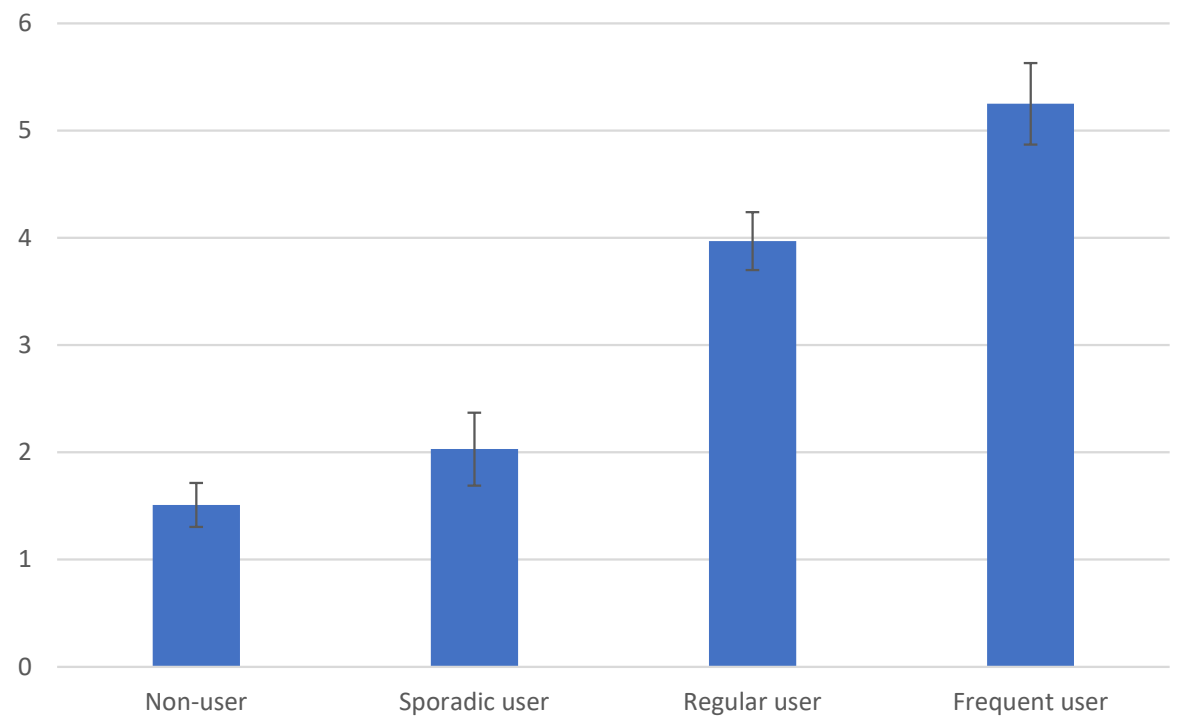

Comments: Error bars: $95 \% \mathrm{Cl}$. Listening to streamed, CD, vinyl, and own digital file. Non-users used no music-streaming services during the last 30 days. Sporadic users did not stream the day before answering the survey, but used at least one streaming service 8-30 days prior. Regular users streamed music the day before but for less than 60 minutes, or they used at least one streaming service during the last 7 days. Frequent users streamed music for more than 60 minutes and also used at least one streaming service during the last 7 days.

Compared with television streaming, using several music-streaming services is less relevant, as the music libraries of different services largely overlap (Morris \& Powers, 2015). There are, however, differences between types of users and number of services used, with the number of services used during the last 30 days increasing significantly with types of users, $F(2,441.18)=67.88, p<.001$ (Welch's $F$ ). The effect size is medium $\left(\omega^{2}=.09\right)$. Post-hoc comparisons using the Tukey HSD test indicate that the means 
scores for sporadic users $(\mathrm{M}=1.23, \mathrm{SD}=.43)$, regular users $(\mathrm{M}=1.56, \mathrm{SD}=.67)$, and frequent users $(\mathrm{M}=1.87, \mathrm{SD}=.76)$ are significantly different between all groups.

Regarding number of genres streamed - and contrary to what we expected with H1a - frequent streamers do not watch fewer genres compared with other user-types, quite the contrary. For music, results support H1b: Frequent streamers listen to more genres compared with other types of users. Our results support our second hypothesis: Frequent television streamers and music streamers report using more streaming services compared with those who stream less extensively, and these associations are larger for television compared with music.

\section{How do types of streamers differ demographically?}

Figures 6 and 7 depict how age, gender, income, and education are associated with types of streaming users. Cross-tabulations with Chi-square statistics and Cramer's $V$ for effect sizes were calculated (see Tables A1-A8 in Appendix 1). Results indicate that younger people are more likely to be frequent streamers and that older people and females are more likely to be non-streamers. Those with low education are more likely to be non-users of television-streaming services. Low-income respondents are more likely to be both non-users and frequent television streamers. For music, high-income respondents are less likely to be non-users, and low-income respondents are more likely to be frequent users.

Figure 6 Types of television-streaming users by age, gender, income, and education
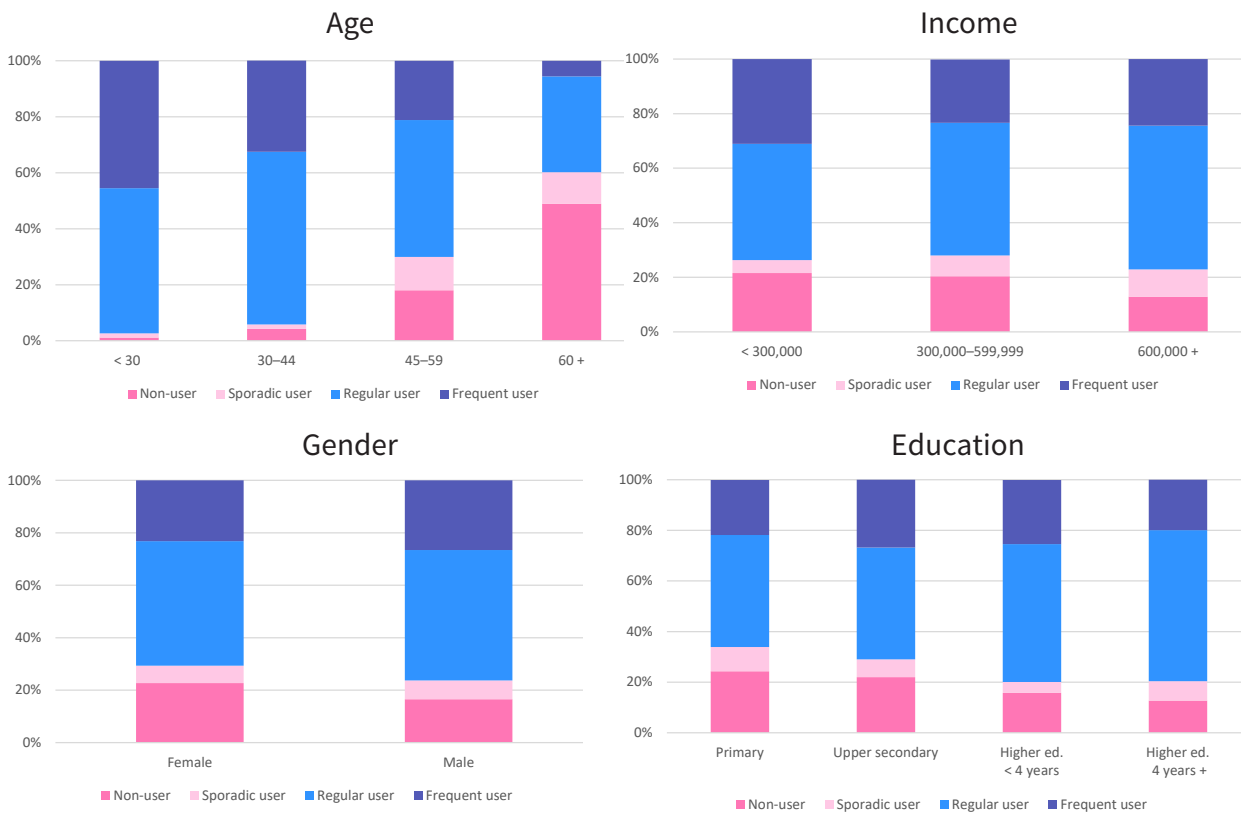

Comments: Non-users used no TV-streaming services during the last 30 days. Sporadic users did not stream the day before answering the survey, but used at least one streaming service 8-30 days prior. Regular users streamed the day before but for less than 120 minutes, or they used at least one streaming service during the last 7 days. Frequent users streamed for more than 120 minutes and also used at least one streaming service during the last 7 days. 
Figure 7 Types of music-streaming users by age, gender, income, and education

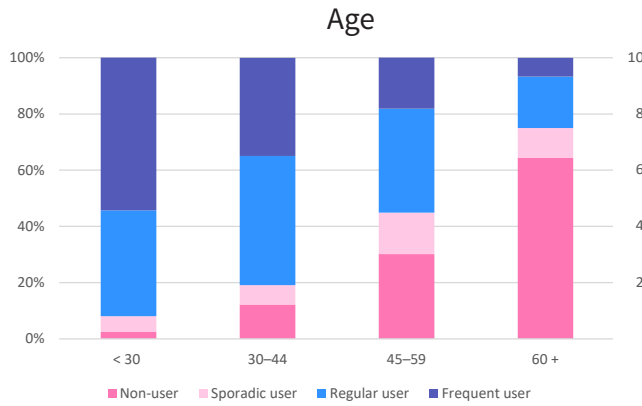

Gender

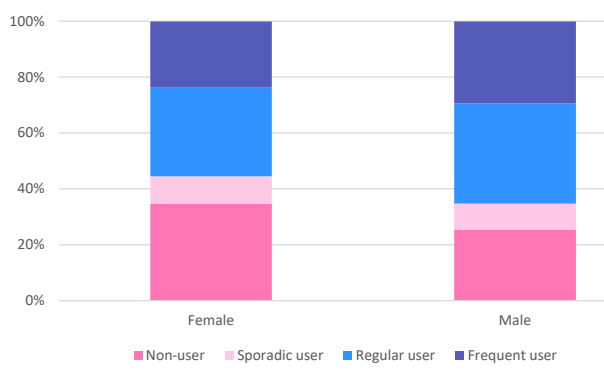

Income

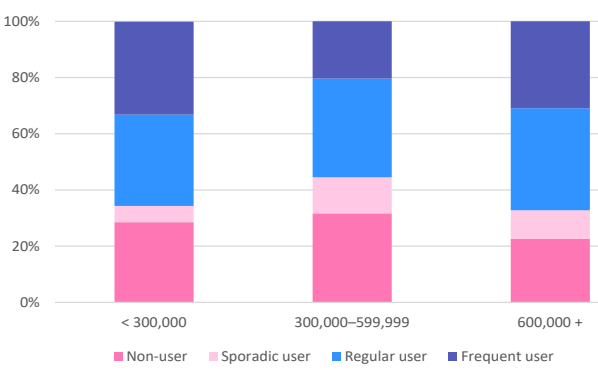

Education

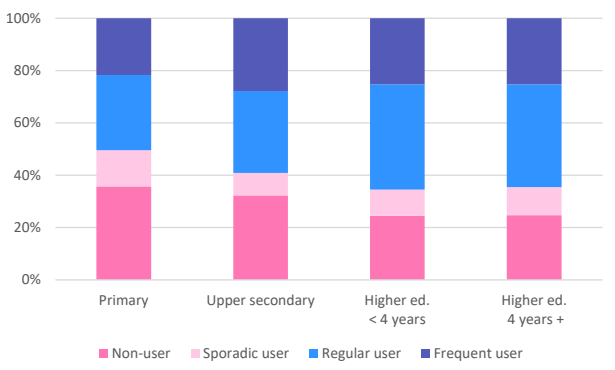

Comments: Non-users used no music-streaming services during the last 30 days. Sporadic users did not stream the day before answering the survey, but used at least one streaming service 8-30 days prior. Regular users streamed the day before but for less than 60 minutes, or they used at least one streaming service during the last 7 days. Frequent users had streamed for more than 60 minutes and also used at least one streaming service during the last 7 days.

Figures 6 and 7 overall suggest that except for the oldest age group, streaming services have become common modes of accessing music and, particularly, television content. The prevalence of streaming is worth noting before proceeding with investigating what demographics characterise frequent streamers (H3). We proceed by including age (as a continuous variable), gender, education, and income (as dichotomous variables) as predictor variables in the multinomial regression models.

Tables 2 and 3 display the results. In both models, non-users are defined as the reference category, implying that the models estimate the likelihood of respondents being sporadic, regular, or frequent users compared with being a non-user, given their scores on the predictor variables. The odds ratios reflect the change in likelihood of belonging to the user segment rather than being a non-user. Odds ratios significantly larger than 1 reflect an increased likelihood of membership in the user segment, compared with not being a user. The odds ratios do not refer to the probability of, for example, females being frequent users, but the likelihood of females being frequent users (relative to non-users) compared with males. 
Marika Lüders, Vilde Schanke Sundet, \& Terje Colbjørnsen

Table 2 Multinomial logistic regression of types of television streamers

\begin{tabular}{|c|c|c|c|c|c|c|c|c|c|}
\hline & \multicolumn{3}{|c|}{ Sporadic users $(N=79)$} & \multicolumn{3}{|c|}{ Regular users $(N=526)$} & \multicolumn{3}{|c|}{ Frequent users $(N=280)$} \\
\hline & $B(\mathrm{SE})$ & OR & $95 \% \mathrm{Cl}$ & $B(\mathrm{SE})$ & OR & $95 \% \mathrm{Cl}$ & $B$ (SE) & OR & $95 \% \mathrm{Cl}$ \\
\hline Age: continuous & $\begin{array}{l}-.04 \\
(.01)^{\star \star \star}\end{array}$ & .96 & $(.94-.98)$ & $\begin{array}{l}-.10 \\
(.01)^{\star \star \star}\end{array}$ & .91 & $(.89-.92)$ & $\begin{array}{l}-.13 \\
(.01)^{\star \star \star}\end{array}$ & .88 & $(.86-.89)$ \\
\hline Gender: female & $\begin{array}{l}-.12 \\
(.27)\end{array}$ & .88 & $(.52-1.51)$ & $\begin{array}{l}-.37 \\
(.19)\end{array}$ & .69 & $(.47-1.01)$ & $\begin{array}{l}-.45 \\
(.23)^{\star}\end{array}$ & .64 & $(.41-.99)$ \\
\hline Education: low & $\begin{array}{l}-.08 \\
(.30)\end{array}$ & .92 & $(.51-1.66)$ & $\begin{array}{l}-.65 \\
(.21)^{\star \star}\end{array}$ & .52 & $(.34-.79)$ & $\begin{array}{l}-.16 \\
(.25)\end{array}$ & .85 & $(.52-1.38)$ \\
\hline Income: low & $\begin{array}{l}-.65 \\
(.35)\end{array}$ & .52 & $(.26-1.03)$ & $\begin{array}{l}-.53 \\
(.24)^{\star}\end{array}$ & .59 & $(.37-.94)$ & $\begin{array}{l}-.58 \\
(.27)^{*}\end{array}$ & .56 & $(.33-.96)$ \\
\hline Intercept & $\begin{array}{l}1.95 \\
(.68)^{\star}\end{array}$ & & & $\begin{array}{l}7.06 \\
(.52)^{\star \star \star}\end{array}$ & & & $\begin{array}{l}7.56 \\
(.56)^{\star \star * *}\end{array}$ & & \\
\hline Model $X^{2}(\mathrm{df})$ & $\begin{array}{c}449.56 \\
(12)^{\star \star \star}\end{array}$ & & & & & & & & \\
\hline$R^{2}$ (Nagelkerke) & .37 & & & & & & & & \\
\hline$R^{2}$ (Cox and Snell) & .34 & & & & & & & & \\
\hline
\end{tabular}

Comments: Reference category: non-users of TV-streaming services $(N=213) . B=$ unstandardised regression coefficient; $\mathrm{SE}=$ standard error; $\mathrm{OR}=\mathrm{odds}$ ratio; $\mathrm{Cl}=$ confidence interval for $\mathrm{OR}$.

${ }^{\star \star \star} p<.001,{ }^{\star \star} p<.01,{ }^{\star} p<.05$

Table 3 Multinomial logistic regression of types of music streamers

\begin{tabular}{|c|c|c|c|c|c|c|c|c|c|}
\hline & \multicolumn{3}{|c|}{ Sporadic users $(N=79)$} & \multicolumn{3}{|c|}{ Regular users $(N=526)$} & \multicolumn{3}{|c|}{ Frequent users $(N=280)$} \\
\hline & $B(\mathrm{SE})$ & OR & $95 \% \mathrm{Cl}$ & $B(\mathrm{SE})$ & OR & $95 \% \mathrm{Cl}$ & $B(\mathrm{SE})$ & OR & $95 \% \mathrm{Cl}$ \\
\hline Age: continuous & $\begin{array}{l}-.05 \\
(.01)^{\star \star \star}\end{array}$ & .95 & $(.94-.97)$ & $\begin{array}{l}-.09 \\
(.01)^{\star \star \star}\end{array}$ & .92 & $(.91-.93)$ & $\begin{array}{l}-.12 \\
(.01)^{\star \star \star}\end{array}$ & .89 & $(.87-.90)$ \\
\hline Gender: female & $\begin{array}{l}-26 \\
(.22)\end{array}$ & .77 & $(.50-1.19)$ & $\begin{array}{l}-.54 \\
(.17)^{\star \star}\end{array}$ & .58 & $(.41-.82)$ & $\begin{array}{l}-69 \\
(.20)^{\star \star \star}\end{array}$ & .50 & $(.34-.74)$ \\
\hline Education: low & $\begin{array}{l}-.19 \\
(.24)\end{array}$ & .82 & $(.52-1.30)$ & $\begin{array}{l}-55 \\
(.18)^{\star \star}\end{array}$ & .58 & $(.40-.83)$ & $\begin{array}{l}-.36 \\
(.21)\end{array}$ & .70 & $(.46-1.01)$ \\
\hline Income: low & $\begin{array}{l}-.63 \\
(.30)^{\star}\end{array}$ & .53 & $(.30-.96)$ & $\begin{array}{l}-.09 \\
(.21)\end{array}$ & .91 & $(.60-1.38)$ & $\begin{array}{l}-.03 \\
(.24)\end{array}$ & .97 & $(.61-1.55)$ \\
\hline Intercept & $\begin{array}{l}2.19 \\
(.49)^{\star \star \star}\end{array}$ & & & $\begin{array}{l}5.34 \\
(.39)^{\star \star \star}\end{array}$ & & & $\begin{array}{l}6.37 \\
(.43)^{\star \star \star}\end{array}$ & & \\
\hline Model $X^{2}(\mathrm{df})$ & $\begin{array}{l}502.31 \\
(12)^{\star \star \star}\end{array}$ & & & & & & & & \\
\hline$R^{2}$ (Nagelkerke) & .37 & & & & & & & & \\
\hline$R^{2}$ (Cox and Snell) & .35 & & & & & & & & \\
\hline
\end{tabular}

Comments: Reference category: non-users of music streaming services $(N=345) . B=$ unstandardised regression coefficient; $\mathrm{SE}=$ standard error; $\mathrm{OR}=$ odds ratio; $\mathrm{Cl}=$ confidence interval for $\mathrm{OR}$.

${ }^{\star \star \star} p<.001,{ }^{\star \star} p<.01,{ }^{\star} p<.05$

The likelihood ratio tests showed that for both models, including the predictor variables significantly account for more variability in the outcome variable [for types of television streamers, $X^{2}(12)=449.56, p<.001$; for types of music streamers, $X^{2}(12)=502.31, p$ $<.001] . R^{2}$ measures (Nagelkerke; Cox and Snell) are similar and between .34 and .37 .

Age significantly predicts types of streamers, and increasingly so for each category of user. For example, older age is negatively associated with being a frequent television streamer compared with being a non-user $\left[B=-.13\right.$, Wald $\left.X^{2}(1)=218.04, p<.001\right]$. 
The odds of being a frequent user rather than a non-user is about 12 per cent lower for each year of age $(\mathrm{OR}=.88,95 \% \mathrm{CI}=.86-.89)$. Test statistics are very similar for music streamers, hence supporting $\mathrm{H} 3 \mathrm{a}$.

Gender significantly predicts being a frequent television streamer compared with being a non-user $\left[B=-.45\right.$, Wald $\left.X^{2}(1)=4.02, p<.001\right]$. Females are 36 per cent less likely than males to be frequent streamers $(\mathrm{OR}=.64,95 \% \mathrm{CI}=.41-.99)$. Gender likewise predicts being a frequent music streamer compared with being a non-user $[B=-.69$, Wald $\left.X^{2}(1)=12.23, p<.001\right]$. Females are 50 per cent less likely than males to be frequent streamers of music $(\mathrm{OR}=.50,95 \% \mathrm{CI}=.34-.74)$. Our results therefore support $\mathrm{H} 3 \mathrm{~b}$.

Education significantly predicts being a regular television and music streamer compared with being a non-user: those with low education are less likely to be regular users compared with those with higher education. For other categories, education has no significant effects. We did not expect frequent users to differ regarding educational attainment. Hence, although education predicts being a regular streamer, our results align with what we expected with $\mathrm{H} 3 \mathrm{c}$.

Lastly, income significantly predicts being a regular and frequent television streamer compared with being a non-user. Income level predicts frequent streamers relative to non-streamers $\left[B=-.58\right.$, Wald $\left.X^{2}(1)=4.41, p<.05\right]$. Those with low income are 44 per cent less likely than those with higher income to be frequent television streamers $(\mathrm{OR}=$ $.56,95 \% \mathrm{CI}=.33-.96$ ). For music streaming, income significantly predicts being a sporadic user relative to a non-user. For other categories, income has no significant effects. We did not expect frequent users to differ regarding level of income. H3d is therefore supported for music streaming, but not for television streaming.

Summarising results, young males with high income are more likely than others to be frequent television streamers rather than non-users. Regarding music streaming, both age (youth) and sex (male) are significant predictors of being frequent streamers compared with non-users. While the cross tabulations indicate that low income is associated with being frequent streamers, the multinomial logistic regressions control for the other predictive variables (Denham, 2002), and suggest that the initial association likely relates to a relatively larger share of younger respondents belonging to the low-income category.

\section{Do users belong to the same category of streamers across industries?}

The above results depict frequent television streamers and music streamers as demographically similar. We examine whether users also tend to belong to the same types of streamers across industries by first cross-tabulating users. We first turn to frequent users across industries. Table 4 shows that this includes 115 users. With a total of 296 frequent music streamers, 39 per cent of these are also frequent television streamers. With 267 frequent television streamers, 43 per cent of these are also frequent music streamers. There is additionally a clear pattern where frequent music streamers tend to be at least regular users of television-streaming services, with a similar pattern for frequent television streamers. If we consider overlaps between types more broadly, we further see a clustering of users as non-users and regular users across music- and television-streaming services. The association between types of streamers across industries was investigated using Spearman's rho for correlation $(r h o=.496, p<.001)$ implying a medium-sized correlation. 
Table 4 Distribution of users for television- and music-streaming services

\begin{tabular}{llccccc}
\hline & & \multicolumn{4}{c}{ Television streaming } \\
\multirow{3}{*}{ Music } & non-user & sporadic & regular & frequent & total \\
streaming & non-user & 193 & 42 & 85 & 24 & 344 \\
& sporadic & 14 & 20 & 52 & 23 & 109 \\
& regular & 25 & 10 & 224 & 105 & 364 \\
& frequent & 5 & 13 & 163 & 115 & 296 \\
& total & 237 & 85 & 524 & 267 & 1,113 \\
\hline
\end{tabular}

Comments: Number of users for each category drops compared with initial categorisation, since the cross-table only includes respondents who could be categorised on both variables.

\section{Discussion}

This study captures a historically significant time with users turning to online content libraries to access media content. Our results hence indicate the status of Norwegian streamers in October 2018, but we will discuss what our results may imply in terms of future development.

First, frequent streamers consume a wider variety of genres. We tested our hypotheses with data on total number of television genres (linear and streamed) and music genres (streamed, CD, vinyl, and own digital files), and as such, these results are not an outcome of how we defined frequent users. We also find that frequent television users stream more genres compared with the number of genres they watch on linear television, and that regular users come across as more dual linear/stream users (Figures 3 and 4). For television, the variety of genres consumed by frequent users may point to the limitations of considering binge viewing as a proxy for understanding how people stream television (Merikivi et al., 2018; Pittman \& Sheehan, 2015; Steiner \& Xu, 2018; Sung et al., 2018). Viewers who predominantly watch full seasons of productions within a compressed timeframe would consequently watch fewer genres. Frequent streamers thus use selfscheduling opportunities to compose personal and diverse content repertoires. While not reported in the analysis, news/debates and sports unsurprisingly still hold a strong position as linear content. Yet television-streaming services mirror the content of linear television, and users will likely continue to expand the number of genres consumed online. For music, we expected and found that frequent streamers listen to more genres. Our measure here does not distinguish between how users listened to music (though excluding listening to music on radio). However, unlike television consumption, where streaming and linear modes of watching are both prevalent, listening to music on CD, vinyl, or one's own digital file is relatively uncommon (Schiro, 2020).

What people choose to stream is an outcome of both how these services are structured and user agency. Users are as such granted autonomy, but since service providers devise paths through content libraries by way of interfaces, menus, and personalisation (Johnson, 2019; Morris \& Powers, 2015), this is simultaneously a constrained autonomy. A central question that we can only tentatively address is whether these diverse consumption patterns are outcomes of users working with or against the structuring forces of streaming services. Findings from a qualitative study of television streamers at least point to a common perception of how interfaces and personalisation appear structured 
to inhibit diversity of content (Lüders \& Sundet, 2021), and as such, provides some evidence for the genre-diversity we find here as a result of users working against the logics of streaming.

Second, frequent streamers report using more services compared with those who stream less extensively, and as we expected, such patterns are more prominent for television streaming. We may tentatively consider use of several services as related to an experienced need for more diverse content. These findings are also important in a context where new services are launched to get their share of paying subscribers (e.g., Apple TV+, Disney+). The importance of content acquisition in the competition for viewers (Johnson, 2019), and the need for users to turn to several providers in order to access exclusive content, will likely only increase in scope. The use of multiple services by frequent users may indicate an inclination to continuously turn to additional providers, but even in affluent Norway, streaming services will likely face challenges regarding how many services users are willing to pay for. This might also imply that cable and satellite will remain important for years to come, with viewers complementing a wider variety of channels available with a few selected streaming services. The situation is different for music streaming, where providers to a very limited extent compete on content libraries (Morris \& Powers, 2015), and where relying on one streaming service suffices even for the most avid listeners (or even just ad-supported YouTube for more casual listeners).

Third, those who use television- and music-streaming services most extensively tend to be younger males. Level of education is of limited importance, but higher income is associated with frequent use of television streaming. More importantly, however, results indicate that streaming is becoming a dominant mode of accessing media content. Hence, a key finding is the ordinariness of being a streamer; streaming has gone from a first-mover activity to a standard consumer mode. The broad picture is that regular and frequent streamers are found across demographic variables (see Figures 6 and 7). It is worth noting that 20 and 30 per cent are non-users of television- and music-streaming services (see Figure 1). This does not imply that the potential for growth is higher for music streaming; since the music sector has already experienced a transition to streaming as a dominant model, a continued substantial increase in users and frequent users may be unlikely. The television domain, however, is probably in a transitional phase. The share of regular and frequent television streamers is already substantial, and while younger males dominate as frequent streamers, we expect such demographic differences to become much less salient over the next few years.

Finally, we found a substantial overlap between user categories across industries. While not all frequent television streamers are frequent music streamers (and vice versa), a considerable share of respondents are regular and frequent streamers across industries. There could be spill-over effects at play here, and perhaps particularly from music to television streaming. Since streaming has been the dominant model for accessing music for years, changes in behaviour regarding accessing music may have influenced subsequent behaviours towards accessing television content. While our data do not allow for investigating such longitudinal cross-media dynamics, our study could indicate that users already familiar with streaming as a mode of accessing music were inclined to incorporate television-streaming services as their primary mode of watching television. Hence, while television streaming services carry associations with viewing linear 
television (Johnson, 2019), they also carry associations with streaming as a distribution model, and one in which music streaming has been pivotal in forming user expectations.

\section{Conclusion}

What is the point of investigating users and media use in a situation marked by change? Moving targets are symptomatic for research on new media technologies. Yet, exactly because our target continues to move, documenting its trajectory is crucial. Studies show how industry executives and decision-makers increasingly rely on "industry lore" and "constructed audiences" in times of change (Ang, 1991; Havens, 2014) and how streaming creates such an era of uncertainty (Burroughs, 2019). This furthermore stresses the importance of studying users. Hence, this study examines how Norwegians used streaming services in 2018, but results may be indicative for future development, and consequently also for research directions. The ordinariness of streaming points to how studies must include different modes of accessing content in order to reflect media use. Examining media use patterns as contingent on types of streamers conveys more nuanced implications of streaming, and focusing on frequent users enables an analysis of users most likely to be impacted by the logics of streaming. However, when we find that frequent streamers consume a wider variety of genres, this possibly also relates to affinity to television and music, respectively. While our study applies a granular distinction of users (beyond use/non-use), future studies might therefore benefit from including additional predictive constructs, and from studying who selects what content under what conditions. Additionally, qualitative studies are needed, as these enable nuanced accounts of experiences beyond the grasp of survey-based approaches. Finally, our study indicates a continued move towards streaming in the television industry, but less so in the music industry, which seems more mature and consolidated. In this context, analysing media use as also informed by different industry logics may help build explanatory models of how media users are produced, and how they are produced differently depending on maturity of markets.

\section{Funding}

This article is produced in association with the University of Oslo research project "Streaming the culture industries", funded by the Research Council of Norway (grant number 263076).

\section{Notes}

1. The listed genres were TV-series, film, news and debates, documentaries, sport, e-sport/gaming, talk shows, animation, entertainment, and lifestyle. These genres hence exclude YouTube-specific genre-innovations (e.g., tutorials, make-up videos, memes). The exception is e-sport/gaming, which has crossed over to linear television.

2. The listed genres were Blues, Funk, Country/Western, Electronica/EDM, House, Trance, Alternative, Indie, Punk, Jazz, Folk music, Classical, Opera, Pop, RnB, Rap, Hip-hop, Reggae/Ska, Metal, Rock, Contemporary, Singer-songwriter, and World music. These genres hence follow established ways of categorising music, yet it should be noted that streaming services additionally include categories such as mood-based and situation-specific music.

3. Categorising users solely based on time spent streaming the day before answering the survey is not a viable option, since respondents may have happened to not stream the day before answering the survey and still use such services regularly. Hence the need to also consider time since using streaming services (last 7 days and $8-30$ days). 
Towards streaming as a dominant mode of media use?

4. Notice that the means for total number of genres do not equal the sum of means for streamed genres and means for linear genres. If a respondent, for example, had watched TV-series both streamed and linear, this was counted as one in total number of genres.

\section{References}

Ang, I. (1991). Desperately seeking the audience. London: Routledge. https://doi.org/10.4324/9780203133347

Beer, D. (2019). The quirks of digital culture. West Yorkshire: Emerald Group Publishing.

Bruun, H. (2020). Re-scheduling television in the digital era. London: Routledge. https://doi. org/10.4324/9780429276309

Burroughs, B. (2019). House of Netflix: Streaming media and digital lore. Popular Communication, 17(1), 1-17. https://doi.org/10.1080/15405702.2017.1343948

Colbjørnsen, T. (2020, October 27). The streaming network: Conceptualizing distribution economy, technology, and power in streaming media services. Convergence. OnlineFirst. https://doi. org/10.1177/1354856520966911

Denham, B. E. (2002). Advanced categorical statistics: Issues and applications in communication research. Journal of Communication, 52(1), 162-176. https://doi.org/10.1111/j.1460-2466.2002.tb02537.x

Denham, B. E. (2010). Measurement of risk perceptions in social research: A comparative analysis of ordinary least squares, ordinal and multinomial logistic regression models. Journal of Risk Research, 13(5), 571-589. https://doi.org/10.1080/13669870903172386

Gerpott, T. J., \& Meinert, P. (2019). Not just every user of mobile music streaming shares the same characteristics: A classification analysis of mobile network operator subscribers in Germany. Telematics and Informatics, 41, 19-33. https://doi.org/10.1016/j.tele.2019.01.008

Hagen, A. N. (2015). The playlist experience: Personal playlists in music streaming services. Popular Music and Society, 38(5), 625-645. http://dx.doi.org/10.1080/03007766.2015.1021174

Hagen, A. N., \& Lüders, M. (2017). Social streaming? Navigating music as personal and social. Convergence, 23(6), 643-659. https://doi.org/10.1177/1354856516673298

Havens, D. (2014). Media programming in the era of big data. Media Industries, 1(2), 1-5. https://doi. org/10.3998/mij.15031809.0001.202

Havens, D., \& Lotz, A. D. (2012). Understanding media industries. Oxford: Oxford University Press.

Herbert, D., Lotz, A. D., \& Marshall, L. (2019). Approaching media industries comparatively: A case study of streaming. International Journal of Cultural Studies, 22(3), 349-366. https://doi. org/10.1177/1367877918813245

Hesmondhalgh, D. (2019). The cultural industries (4th ed.). London: Sage.

Hjertaas, I. S. (2019). TV-mediet $i$ endring - NRK og TV2 $i$ en strømmetid [Television in transition - NRK and TV2 in the era of streaming] [Master's thesis, Høgskolen i Innlandet, Norway]. https://brage.inn. no/inn-xmlui/handle/11250/2619635

Johnson, C. (2019). Online TV. London: Routledge. https://doi.org/10.4324/9781315396828

Kjus, Y. (2016). Musical exploration via streaming services: The Norwegian experience. Popular Communication, 14(3), 127-136. http://dx.doi.org/10.1080/15405702.2016.1193183

Leung, L., \& Chen, C. (2017). Extending the theory of planned behavior: A study of lifestyles, contextual factors, mobile viewing habits, TV content interest, and intention to adopt mobile TV. Telematics and Informatics, 34(8), 1638-1649. https://doi.org/10.1016/j.tele.2017.07.010

Li, S.-C. S. (2020). Lifestyles, technology clustering, and the adoption of over-the-top television and Internet protocol television in Taiwan. International Journal of Communication, 14, 2017-2035. https://ijoc.org/ index.php/ijoc/article/view/12259/3039

Lobato, R. (2019). Netflix nations: The geography of digital distribution. New York: NYU Press.

Lotz, A. D. (2017). Portals: A treatise on Internet-distributed television. Ann Arbor, Michigan: Michigan Publishing. http://dx.doi.org/10.3998/mpub.9699689

Lotz, A. D. (2018). We now disrupt this broadcast: How cable transformed television and the Internet revolutionised it all. Cambridge, Massachusetts: MIT press

Lüders, M. (2019, July 28). Pushing music: People's continued will to archive versus Spotify's will to make them explore. European Journal of Cultural Studies. OnlineFirst. https://doi.org/10.1177/1367549419862943

Lüders, M. (2020, May 5). Ubiquitous tunes, virtuous archiving and catering for algorithms: The tethered affairs of people and music streaming services. Information, Communication \& Society, 1-17. Aheadof-print. https://doi.org/10.1080/1369118X.2020.1758742

Lüders, M., \& Sundet, V. S. (2021). Conceptualizing the experiential affordances of watching online TV. Manuscript submitted for publication.

Merikivi, J., Salovaara, A., Mäntymäki, M., \& Zhang, L. (2018). On the way to understanding binge watching behavior: The over-estimated role of involvement. Electronic Markets, 28(1), 111-122. https://doi. 
org/10.1007/s12525-017-0271-4

Moe, H., Hovden, J. F., \& Karppinen, K. (2020, October 29). Operationalizing exposure diversity. European Journal of Communication. OnlineFirst. https://doi.org/10.1177/0267323120966849

Morris, J. W., \& Powers, D. (2015). Control, curation and musical experience in streaming music services. Creative Industries Journal, 8(2), 106-122. https://doi.org/10.1080/17510694.2015.1090222

Nowak, R. (2016). When is a discovery? The affective dimensions of discovery in music consumption. Popular Communication, 14(3), 137-145. https://doi.org/10.1080/15405702.2016.1193182

Oyedele, A., \& Simpson, P. M. (2018). Streaming apps: What consumers value. Journal of Retailing and Consumer Services, 41, 296-304. https://doi.org/10.1016/j.jretconser.2017.04.006

Pittman, M., \& Sheehan, K. (2015). Sprinting a media marathon: Uses and gratifications of binge-watching television through Netflix. First Monday, 20(10), n.p. https://doi.org/10.5210/fm.v20i10.6138

Prior, M. (2005). News vs. entertainment: How increasing media choice widens gaps in political knowledge and turnout. American Journal of Political Science, 49(3), 577-592. https://doi.org/10.2307/3647733

Rogers, E. M. (2003). Diffusion of Innovations (5th ed.). New York: Free Press.

Schiro, E. C. (2020). Norsk mediebarometer 2019 [Norwegian media barometer 2019]. Statistics Norway. https://www.ssb.no/kultur-og-fritid/artikler-og-publikasjoner/_attachment/421056?_ts=1722704ab88

Schrøder, K. C. (2015). News media old and new: Fluctuating audiences, news repertoires and locations of consumption. Journalism studies, 16(1), 60-78. https://doi.org/10.1080/1461670X.2014.890332

Sinclair, G., \& Tinson, J. (2017). Psychological ownership and music streaming consumption. Journal of Business Research, 71, 1-9. https://doi.org/10.1016/j.jbusres.2016.10.002

Sinnreich, A. (2016). Slicing the pie: The search for an equitable recorded music economy. In P. Wikström, \& R. DeFillippi (Eds.), Business innovation and disruption in the music industry (pp. 153-174). Cheltenham, UK: Edward Elgar Publishing.

Sjøvaag, H. (2016). Media diversity and the global superplayers: Operationalising pluralism for a digital media market. Journal of Media Business Studies, 13(3), 170-186. https://doi.org/10.1080/16522354 .2016 .1210435

Smith, M. D., \& Telang, R. (2016). Streaming, sharing, stealing: Big data and the future of entertainment. Cambridge, Massachusetts: MIT Press.

Spilker, H. S., \& Colbjørnsen, T. (2020). The dimensions of streaming: Toward a typology of an evolving concept. Media, Culture \& Society, 42(7-8), 1210-1225. https://doi.org/10.1177/0163443720904587

Steiner, E., \& Xu, K. (2018). Binge-watching motivates change: Uses and gratifications of streaming video viewers challenge traditional TV research. Convergence, 26(1), 82-101. https://doi. org/10.1177/1354856517750365

Sundet, V. S. (2016). Still 'Desperately seeking the audience'? Audience making in the age of media convergence (the Lilyhammer experience). Northern Lights, 14(1), 11-27. https://doi.org/10.1386/nl.14.1.11_1

Sung, Y. H., Kang, E. Y., \& Lee, W.-N. (2018). Why do we indulge? Exploring motivations for binge watching. Journal of Broadcasting \& Electronic Media, 62(3), 408-426. https://doi.org/10.1080/08838151. 2018.1451851

Tefertiller, A. (2018). Media substitution in cable cord-cutting: The adoption of web-streaming television. Journal of Broadcasting \& Electronic Media, 62(3), 390-407. https://doi.org/10.1080/08838151.201 8.1451868

Turner, G. (2019). Approaching the cultures of use: Netflix, disruption and the audience. Critical Studies in Television, 14(2), 222-232. https://doi.org/10.1177/1749602019834554

Wikström, P. (2013). The music industry: Music in the Cloud (2nd edition). Cambridge, UK: Polity.

(C) 2021 Nordicom and respective authors. This is an Open Access work licensed under the terms of the Creative Commons Attribution-NonCommercial-NoDerivatives 4.0 International Public licence (CC BY-NC-ND 4.0). To view a copy of the licence, visit https://creativecommons.org/ licenses/by-nc-nd/4.0/ 


\section{Appendix 1}

Table A1 Types of television streamers by age (per cent)

\begin{tabular}{lrrrrr}
\hline & $<\mathbf{3 0}$ & $\mathbf{3 0 - 4 4}$ & $\mathbf{4 5 - 5 9}$ & $\mathbf{6 0}+$ & \multicolumn{1}{c}{ Total } \\
\hline Non-user & 1.1 & 4.2 & 18.0 & 48.9 & $19.7(245)$ \\
Sporadic user & 1.5 & 1.6 & 11.9 & 11.3 & $6.9(86)$ \\
Regular user & 51.9 & 61.7 & 48.9 & 34.2 & $48.6(605)$ \\
Frequent user & 45.5 & 32.6 & 21.2 & 5.6 & $24.9(310)$ \\
Total & 100.0 & 100.1 & 100.0 & 100.0 & 100.1 \\
$N$ & 268 & 313 & 311 & 354 & 1,246 \\
\hline
\end{tabular}

Comments: Share of user types within each age group. The association between age and types of TV-streamers is significant $\left[X^{2}(9)=418.87, p<.001\right]$. Cramer's $V=.335, p<.001$. People under the age of 30 are more likely to be frequent streamers. People aged 60 years and older are more likely to be non-users.

Table A2 Types of music streamers by age (per cent)

\begin{tabular}{|c|c|c|c|c|c|}
\hline & $<30$ & $30-44$ & $45-59$ & $60+$ & Total \\
\hline Non-user & 2.6 & 12.2 & 30.2 & 64.5 & $30.0(402)$ \\
\hline Sporadic user & 5.5 & 6.9 & 14.7 & 10.5 & $9.6(129)$ \\
\hline Regular user & 37.6 & 46.0 & 37.0 & 18.3 & $33.9(454)$ \\
\hline Frequent user & 54.4 & 34.9 & 18.2 & 6.7 & $26.4(354)$ \\
\hline Total & 100.1 & 100.0 & 100.1 & 100.0 & 99.9 \\
\hline$N$ & 274 & 335 & 341 & 389 & 1,339 \\
\hline
\end{tabular}

Comments: Share of user types within each age group. The association between age and types of music streamers is significant $\left[X^{2}(9)=476.03, p<.001\right]$. Cramer's $V=.344, p<.001$. People under the age of 30 are more likely to be frequent streamers. People aged 60 years and older are more likely to be non-users.

Table A3 Types of television streamers by gender (per cent)

\begin{tabular}{lrrr}
\hline & Male & Female & \multicolumn{1}{c}{ Total } \\
\hline Non-user & 16.5 & 22.7 & $19.6(245)$ \\
Sporadic user & 7.2 & 6.6 & $6.9(86)$ \\
Regular user & 49.7 & 47.5 & $48.6(607)$ \\
Frequent user & 26.6 & 23.2 & $24.9(311)$ \\
Total & 100.0 & 100.0 & 100.0 \\
$N$ & 624 & 625 & 1,249 \\
\hline
\end{tabular}

Comments: Share of user types within each gender. The association between gender and types of TV streamers is significant $\left[X^{2}(3)=8.09, p<.05\right]$. Cramer's $V=.080, p<.05$. Males are less likely to be non-users. For other types of users, gender differences are not significant (standardised residuals smaller than 1.96). 
Marika Lüders, Vilde Schanke Sundet, \& Terje Colbjørnsen

Table A4 Types of music streamers by gender (per cent)

\begin{tabular}{lrrr}
\hline & Male & Female & \multicolumn{1}{c}{ Total } \\
\hline Non-user & 25.4 & 34.6 & $30.0(402)$ \\
Sporadic user & 9.3 & 9.9 & $9.6(129)$ \\
Regular user & 35.9 & 31.9 & $34.0(455)$ \\
Frequent user & 29.3 & 23.5 & $26.4(354)$ \\
Total & 99.9 & 99.9 & 100.0 \\
$N$ & 676 & 664 & 1,340 \\
\hline
\end{tabular}

Comments: Share of user types within each gender. The association between gender and types of music streamers is significant $\left[X^{2}(3)=15.43, p<.005\right]$. Cramer's $V=.107, p<.005$. Women are more likely to be non-users. For other types of users, gender differences are not significant (standardised residuals smaller than 1.96).

Table A5 Types of television streamers by education (per cent)

\begin{tabular}{lccccr}
\hline & $\begin{array}{c}\text { Primary } \\
\text { school }\end{array}$ & $\begin{array}{c}\text { Upper } \\
\text { secondary }\end{array}$ & $\begin{array}{c}\text { Higher ed. } \\
<\mathbf{4} \text { years }\end{array}$ & $\begin{array}{c}\text { Higher ed. } \\
\text { 4 years + }\end{array}$ & Total \\
\hline Non-user & 24.3 & 22.0 & 15.8 & 12.7 & $19.6(245)$ \\
Sporadic user & 9.6 & 7.0 & 4.3 & 7.7 & $6.8(85)$ \\
Regular user & 44.3 & 44.2 & 54.5 & 59.7 & $48.6(607)$ \\
Frequent user & 21.7 & 26.8 & 25.3 & 19.9 & $25.0(313)$ \\
Total & 99.9 & 100.0 & 99.9 & 100.0 & 100.0 \\
$N$ & 115 & 701 & 253 & 181 & 1,511 \\
\hline
\end{tabular}

Comments: Share of user types within each level of education. The association between education and types of TV streamers is significant $\left[X^{2}(9)=26.28\right.$, $p<.005]$. Cramer's $V=.084, p<.005$. Those with primary school education are more likely to be non-users. For other types of users, education differences are not significant (standardised residuals are smaller than 1.96)

Table A6 Types of music streamers by education (per cent)

\begin{tabular}{lccccr}
\hline & $\begin{array}{c}\text { Primary } \\
\text { school }\end{array}$ & $\begin{array}{c}\text { Upper } \\
\text { secondary }\end{array}$ & $\begin{array}{c}\text { Higher ed. } \\
<\text { 4 years }\end{array}$ & $\begin{array}{c}\text { Higher ed. } \\
\text { 4 years }+\end{array}$ & \multicolumn{1}{c}{ Total } \\
\hline Non-user & 35.7 & 32.3 & 24.5 & 24.7 & $30.0(402)$ \\
Sporadic user & 13.9 & 8.6 & 10.0 & 10.8 & $9.6(129)$ \\
Regular user & 28.7 & 31.3 & 40.2 & 39.2 & $33.9(454)$ \\
Frequent user & 21.7 & 27.8 & 25.3 & 25.3 & $26.4(354)$ \\
Total & 100.0 & 100.0 & 100.0 & 100.0 & 99.9 \\
$N$ & 115 & 777 & 261 & 186 & 1,339 \\
\hline
\end{tabular}

Comments: Share of user types within each level of education. The association between education and types of music streamers is significant $\left[X^{2}(9)=\right.$ $19.09, p<.05]$. Cramer's $V=.069, p<.05$. The association is only significant for regular users, where those with higher education are more likely to be regular users. 
Table A7 Types of television streamers by income (per cent)

\begin{tabular}{lcccc}
\hline & \multicolumn{1}{c}{ NOK $\mathbf{3 0 0 , 0 0 0}$} & $\begin{array}{c}\text { NOK } \mathbf{3 0 0 , 0 0 0} \\
\mathbf{5 9 9 , 9 9 9}\end{array}$ & NOK 600,000 + & Total \\
\hline Non-user & 21.6 & 20.4 & 12.9 & $19.3(213)$ \\
Sporadic user & 4.7 & 7.6 & 10.0 & $7.3(80)$ \\
Regular user & 42.6 & 48.8 & 52.7 & $47.9(527)$ \\
Frequent user & 31.1 & 23.2 & 24.4 & $25.5(281)$ \\
Total & 100.0 & 100.0 & 100.0 & 100.0 \\
$N$ & 296 & 604 & 201 & 1,101 \\
\hline
\end{tabular}

Comments: Total $N$ is lower because of missing values (respondents who did not want to inform about level of personal income). Share of user types within each level of income. The association between income and types of TV streamers is significant $\left[X^{2}(6)=26.45, p<.01\right]$. Cramer's $V=.09, p<.01$. Those with low income are more likely to be frequent users. At the same time, those with high income are less likely to be non-users. For other types of users, income differences are not significant (standardised residuals are smaller than 1.96).

Table A8 Types of music streamers by income (per cent)

\begin{tabular}{|c|c|c|c|c|}
\hline & & NOK 300,000- & & \\
\hline & $<$ NOK 300,000 & 599,999 & NOK 600,000 + & Total \\
\hline Non-user & 28.5 & 31.7 & 22.6 & 29.1 (345) \\
\hline Sporadic user & 5.8 & 12.8 & 10.2 & 10.4 (123) \\
\hline Regular user & 32.5 & 35.1 & 36.3 & $34.6(411)$ \\
\hline Frequent user & 33.1 & 20.5 & 31.0 & 25.9 (308) \\
\hline Total & 99.9 & 100.1 & 100.1 & 100.0 \\
\hline N & 326 & 635 & 226 & 1,187 \\
\hline
\end{tabular}

Comments: Total $N$ is lower because of missing values (respondents who did not want to inform about level of personal income). Share of user types within each level of income. The association between income and types of music streamers is significant $\left[X^{2}(6)=31.43, p<.001\right]$. Cramer's $V=.115, p<.001$. High-income respondents are less likely to be non-users, and low-income respondents are more likely to be frequent users. For regular users, income differences are not significant (standardised residuals are smaller than 1.96). 